\title{
Role of vacuolar transporter proteins in plant secondary metabolism: Catharanthus roseus cell culture
}

\author{
Sittiruk Roytrakul · Robert Verpoorte
}

Received: 20 July 2005/ Accepted: 4 August 2006/Published online: 6 March 2007

(C) Springer Science+Business Media B.V. 2007

\begin{abstract}
Here the current status of knowledge on some well-characterized transporters located in the vacuolar membrane is reviewed. As different cellular compartments and even different cells may be involved in certain steps of a biosynthetic pathway, the regulation of the flux is not only dependent on structural genes encoding enzymes catabolizing certain steps but also transport has a major regulatory function. The aim of the present review is to give an overview of the present knowledge of transport of secondary metabolites in plants, and to use this information in the context of our knowledge about Catharanthus roseus alkaloid biosynthesis. This should lead to further insight in the possible role of various transporters in the regulation of the biosynthesis of these alkaloids.
\end{abstract}

\footnotetext{
S. Roytrakul $\cdot$ R. Verpoorte Division of Pharmacognosy, Section of Metabolomics, Institue of Biology, Leiden University, Gorlaeus Laboratories, P.O. Box 9502, 2300RA Leiden, The Netherlands

\section{S. Roytrakul ( $\square)$}

National Center for Genetic Engineering and Biotechnology, National Science and Technology Development Agency, 113 Thailand Science Park, Pahonyothin Rd., Klong 1, Klong Luang,

Pathumthani, Thailand

e-mail: sittiruk@biotec.or.th
}

Keywords Catharanthus roseus $\cdot$ Secondary metabolism · Vacuole $\cdot$ Tonoplast $\cdot$ Transporter
Abbreviations
$\mathrm{ABC}$
ATP-binding cassette transporter
$\mathrm{CCCP}$ carbonyl cyanide
DCCD $m$-chlorophenylhydrazone
MDR $N, N$ '-dicyclohexylcarbodiimide
MRP multidrug resistance protein
PDR
TIA multidrug resistance related protein V-ATPase pleiotropic drug resistance proteins V-PPase terpenoid indole alkaloids vacuolar $\mathrm{H}^{+}$-ATPase vacuolar pyrophosphatase

\section{Role of transport in biosynthesis of secondary metabolites in plants}

Plants synthesize a bewildering array of compounds with a variety of physiological roles that are collectively referred to as secondary metabolites or natural products. The compartmentation of synthesis, degradation, and storage of secondary metabolites is achieved by a series of integrated processes controlled mainly by the membranes by virtue of their permeability properties and the different physico-chemical conditions present in the different compartments 
separated by the membranes. Most secondary metabolites are toxic to the plant itself and necessitate effective mechanisms for detoxification and/or compartmentation. Once secondary metabolites have been transported to their storage sites, they may interact with chemicals and/or proteins to form longer-lasting structures, or be degraded by catabolic enzymes and/or chemical reactions for recycling in other metabolic pathways. The most common storage compartment in the cell for secondary metabolites is the vacuole. This compartmentation may improve the efficiency of their production and avoids harmful effects in the cells (Guern et al. 1987; Luckner et al. 1980; Matile 1987; Wink 1997a, b). In this review, we will particularly focus on the transport through the vacuolar membrane, i.e., on the intracellular transport.

The central vacuole is the largest compartment of a mature plant cell and may occupy more than $90 \%$ of the total cell volume. It represents a very large storage space. However, recent results indicate that besides the large central vacuole, several small vacuoles may exist in a plant cell (Jauh et al. 1999; Paris et al. 1996). Molecules stored mainly in the vacuoles include: inorganic salts, such as sodium, potassium, calcium, magnesium, chloride, nitrate and water, enabling the plant to reach a large size and surface area (Blumwald and Gelli 1997; Matile 1987; Martinoia 1992). The vacuole also serves as an internal reservoir of metabolites and nutrients and takes part in cytosolic ion homeostasis (Boller and Wiemken 1986; Guern et al. 1987; Leigh 1997; Matile 1987; Martinoia 1992).

Many transport systems for secondary metabolites such as cardenolides, anthocyanins and indole alkaloids have been investigated in the tonoplast of various plants (Blom et al. 1991; Deus-Neumann and Zenk 1984, 1986; Hopp and Seitz 1987; Martinoia et al. 2000; Mende and Wink 1987; Otani et al. 2005; Renaudin 1989). Three principal mechanisms for vacuolar accumulation of secondary metabolites have been proposed: $\mathrm{H}^{+}$-antiport and electrogenic uniport, ion and conformational trapping, and directly energized mechanisms catalyzed by ATP-Binding Cassette (ABC) transporters (Klein et al. 1996; Li et al. 1995). Of these, the first two mechanisms depend on a preexisting $\mathrm{H}^{+}$-electrochemical potential difference across the vacuolar membrane, generated by V-ATPase and V-PPase (Rea and Sanders 1987; Rea and Poole 1993; Taiz 1992; Sze et al. 1999; Zhen et al. 1997). Alternatively, or in addition, the secondary metabolites may passively equilibrate across the vacuolar membrane and become trapped in the vacuole by protonation, altered configuration due to the acidic environment, isomerization, complexation with ions, binding to phenolics or to the tonoplast, or interaction with other vacuolar constituents, and even crystallization (Böhm and Franke 1982; Constabel et al. 1980; Endress 1994; Hopp and Seitz 1987; Kurdjian 1982; Matile et al. 1970; McCaskill et al. 1988; Nagakawa et al. 1984; Pradier et al. 1988; Rataboul et al. 1985; Renaudin 1981, 1989; Renaudin and Guern 1982).

The two proton pumps located in the plant vacuolar membranes: V-ATPase and V-PPase were found to be important for vacuolar uptake of most solutes (Table 1). These proton pumps are expressed differently amongst plants and tissues (Maeshima 2000; Rea and Poole 1993). Both pumps catalyze electrogenic $\mathrm{H}^{+}$-translocation from the cytosol into the vacuole to establish an inside-acid $\mathrm{pH}$ gradient $(\Delta \mathrm{pH})$ and an inside-positive electric potential difference $(\Delta \psi)$. This generated electrochemical gradient can be utilized to accumulate cations by a proton antiport mechanism of anions due to the membrane potential difference. The one known mechanism for the transport of secondary metabolites that is not obligatorily dependent on the V-ATPase and $\mathrm{V}$-PPase, has the most recently been discovered: MgATP-energized transport by an ATP-binding cassette (ABC) transporter (Martinoia et al. 2001; Rea et al. 1998; Rea 1999). Progress in characterizing the role of $\mathrm{ABC}$ transporters in plants is very rapid, after the isolation of $\mathrm{ABC}$ genes. Sequence and expression information together with detailed biochemical studies led to new insight on the functions of these transporters. The fact that plant alkaloids such as vincristine, taxol, scopolamine and berberine are often substrates for, or inhibitors of MDR proteins suggests a role of plant $\mathrm{ABC}$ transporters in synthesis and compartmentation of these compounds (Horio et al. 1988; Maeng et al. 2002; Walle and 
Table 1 Reported characterized of V-ATPase and V-PPase transporters in plant

\begin{tabular}{llll}
\hline Transporter & Species & Transported molecules & References \\
\hline V-ATPase & Beta vulgaris & Glucosylated p-hydroxycinnamic acid & Bartholomew et al. (2002) \\
& Beta vulgaris & Salicylic acid 2-O- $\beta$-D-glucose & Dean and Mills (2004) \\
& Catharanthus roseus & Inorganic phosphate & Massonneau et al. (2000) \\
& Coptis japonica & Berberine & Otani et al. (2005) \\
& Daucus carota & Anthocyanin & Hopp and Seitz (1987) \\
& Fumaria capreolata & (S)-Reticuline & Deus-Neumann and Zenk (1986) \\
& Hordeum vulgare & Esculin & Werner and Matile (1985) \\
& Hordeum vulgare & Saponarin, isovitexin & Klein et al. (1996) \\
& Lupinus polyphyllus & Lupanin & Mende and Wink (1987) \\
& Melilotus alba & O-coumaric glucoside & Rataboul et al. (1985) \\
& Petroselinum hortense & Apigenin-7-(6-O-malonyl) glucoside & Matern et al. (1986) \\
& Calendula officinalis & 3-O-monoglucoside of oleanolic acid & Szakiel and Zowska 2002 \\
& Vitis vinifera & Malate, tartrate & Terrier et al. (1998) \\
\hline
\end{tabular}

Walle 1998). There is increasing evidences to support this hypothesis, for example, studies of alkaloids transport in Thalictrum minus cells (Terasaka et al. 2003) and Coptis japonica cells (Yasaki et al. 2001). Several examples of characterized plant MDR-, MRP- and PDR-type ABC transporters are summarized in Table 2.

\section{Diversity of vacuolar transporters}

Recent investigations have shown that the energetics and kinetics of the uptake mechanism depend not only upon the source of secondary metabolite but also the plant species from which the vacuoles were isolated. More than one type of transporter/channel exists at the vacuolar membrane, responsible for specific endogenous compounds and/or compounds synthesized by different plants. The transport of secondary metabolites and/or xenobiotics across the vacuolar membrane is determined by the ligand to which they are conjugated. Polyphenolic acids (Regnault-Roger et al. 2004), flavonols (Jones and Vogt 2001), monoterpenes (Sefton et al. 1994), sesquiterpenes (Castillo et al. 1999), flavonoids (Geibel 1995) and hydroxybenzoic acids (Klick and Herrmann 1988; Yazaki et al. 1995) accumulate as both aglycones and glycosides, whilst alkaloids rarely accumulate as glycosides (Warzecha et al. 1999). Szakiel and Janiszowska (2002) demonstrated that two endogenous oleanolic acid monoglycosides distinctly differed in their mechanism of transport to the vacuole in Calendula officinalis cells. The monoglucoside is transported by an active proton pump whereas the corresponding monoglucuronide is taken up by a passive, carrier-mediated process (Szakiel and Janiszowska 2002).

Martinoia et al. (2001) speculated that naturally occurring glucosylated plant secondary metabolites enter the vacuole by $\mathrm{H}^{+}$-antiport, whereas complex glucosides such as glucosylated xenobiotics are either transported into vacuoles or enter via $\mathrm{ABC}$ transporters, possibly MRPsubclass glutathione conjugate pumps. This has been supported by the results of comparative analyses of flavone glucoside uptake into barley and Arabidopsis vacuoles. The transport of saponarin into barley vacuoles occurs by an $\mathrm{H}^{+}$antiporter but is directly energized by ABC-type transporters in the non-saponarin producing plant, Arabidopsis (Fragne et al. 2002). Similar findings have been reported, for a glucosylated herbicide and for glucosylated $p$-hydroxycinnamic acid that are transported into vacuoles isolated from red beet (Beta vulgaris) by the V-ATPase pump, whereas the glutathionated herbicide and glutathionated $p$-hydroxycinnamic acid are transported by an $\mathrm{ABC}$ transporter (Bartholomew et al. 2002). Recently, Dean and Mills (2004) suggested that salicylic acid 2-O- $\beta$-D-glucose (SAG) was transported into the tonoplast vesicles isolated from soybean (Glycine max L.) via an $\mathrm{ABC}$ transporter but in red beet cells, the vacuolar uptake of SAG occurs through a $\mathrm{H}^{+}$-antiporter mechanism. 


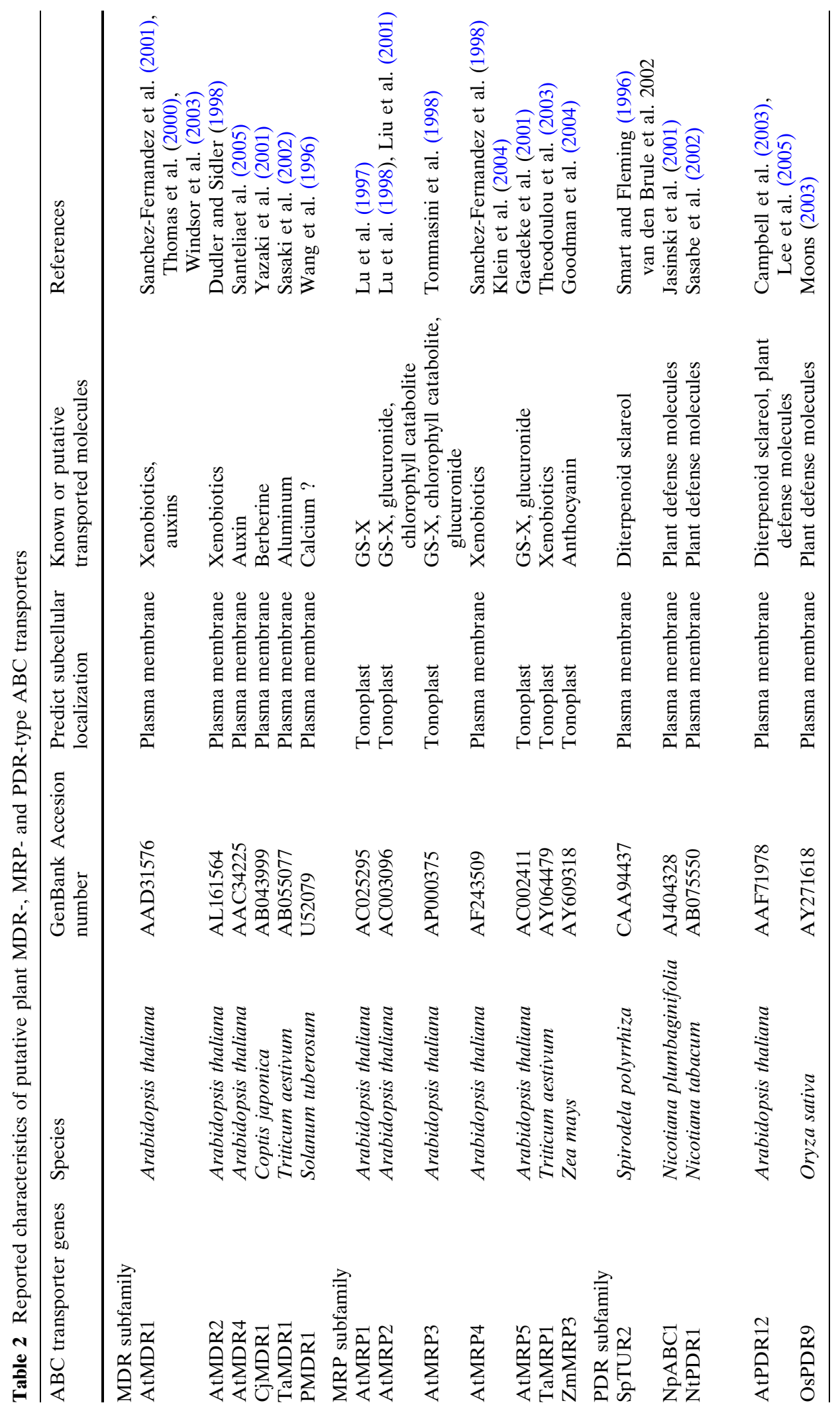


The results of these studies indicate that it is the identity of the ligand, glucose, glutathione or glucuronide to which the parent compound is attached that primarily determines which carrier the conjugate interacts with. A consequence of this is that xenobiotics and endogenous plant secondary metabolites can share common carriers if they are conjugated to the same ligand, even if they bear little structural resemblance to each other (Bartholomew et al. 2002).

\section{Terpenoid indole alkaloid biosynthesis in Catharanthus roseus}

Catharanthus roseus(L.) G. Don, Madagascar periwinkle, is one of the most extensively investigated medicinal plants. The pharmaceutical importance of this plant is due to the presence of two antitumor alkaloids, vincristine and vinblastine, as well as the compounds ajmalicine and serpentine that improve blood circulation in the

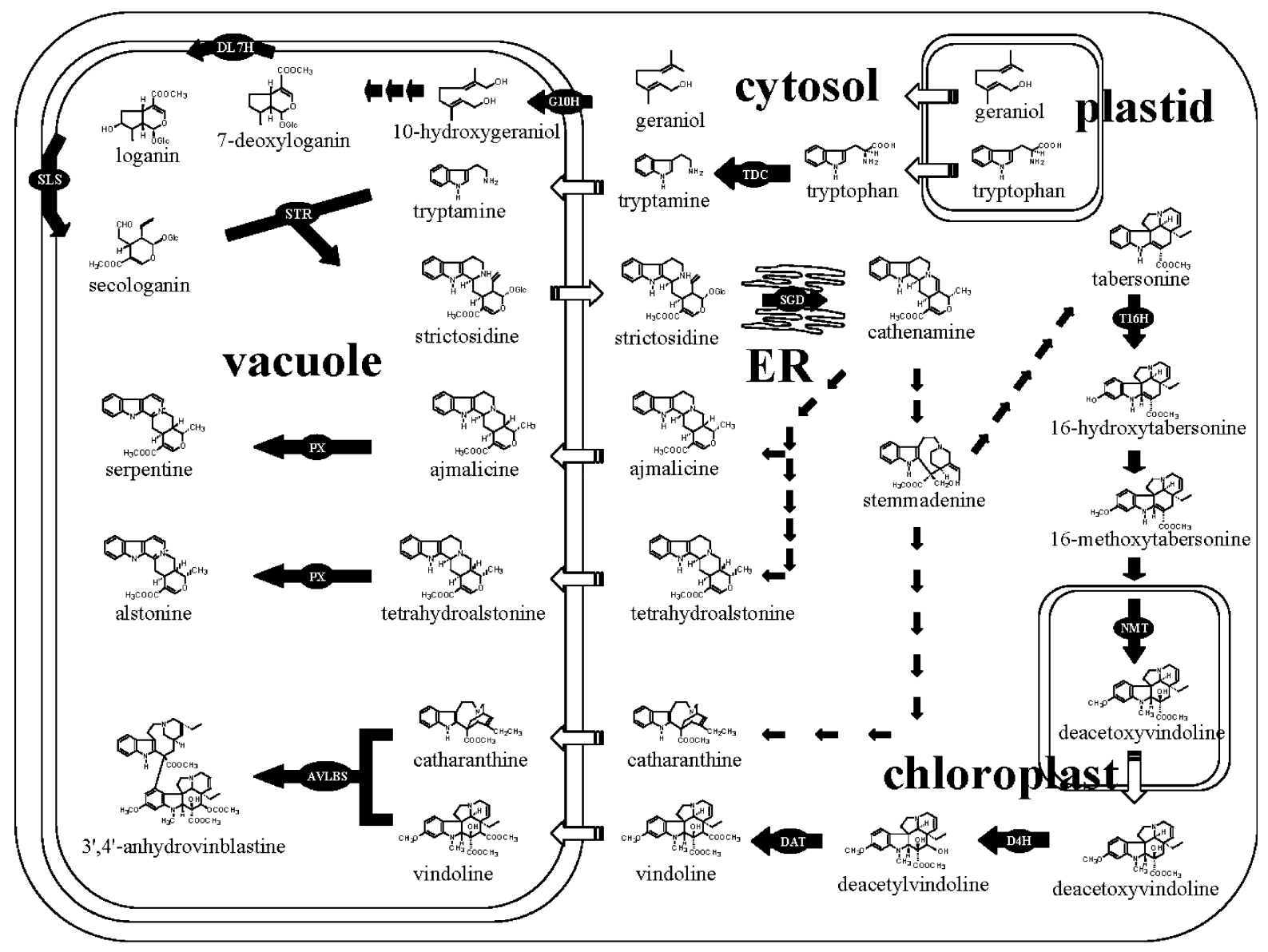

Fig. 1 Subcellular compartmentation of terpenoid indole alkaloid biosynthesis in Catharanthus roseus leading to the corynanthe, aspidosperma and iboga type of alkaloids, which are derived from the central intermediate strictosidine. Cathenamine is converted to ajmalicine and tetrahydroalstonine by several enzymatic steps. Stemmadenine is transformed to catharanthine and vindoline and coupled enzymatically to yield dimeric indole alkaloids like vinblastine. G10H, Geraniol-10-hydroxylase; DL7H, Deoxyloganin 7-hydroxylase; SLS, secologanin synthase; TDC, tryptophan decarboxylase; STR, strictosidine synthase; SGD, Strictosidine glucosidase; T16H, Tabersonine 16-hydroxylase; D4H, desacetoxyvindoline 4-hydroxylase; NMT, $N$-methyltransferase; DAT, deacetylvindoline 4-O-acetyltransferase; AVLBS, Anhydrovinblastine synthase. G10H, DL7H and SLS are assumed to be localized in the tonoplast membrane. Solid lines represent single reactions, dashed lines represent multiple reactions. Solid lines represent single reactions, dashed lines represent multiple reactions. Empty arrow indicate the transport across subcellular membranes 
Table 3 Enzymes specifically involved in Catharanthus alkaloid biosynthesis

\begin{tabular}{|c|c|c|c|}
\hline Enzyme & Abbreviation & $\begin{array}{l}\text { Predicted } \\
\text { subcellular localization }\end{array}$ & References \\
\hline Trytophan decarboxylase & TDC & Cytosol & De Luca et al. (1989) \\
\hline Deoxyloganin 7-hydroxylase & DL7H & Microsome/tonoplast & Irmler et al. (2000) \\
\hline Secologanin synthase & SLS & Microsome/tonoplast & Irmler et al. (2000) \\
\hline Geraniol 10-hydroxylase & $\mathrm{G} 10 \mathrm{H}$ & Provacuolar membrane & Madyastha et al. (1977) \\
\hline Strictosidine synthase & STR & Vacuole & McKnight et al. (1991) \\
\hline Strictosidine $\beta$-D-glucosidase & SGD & Tonoplast/ER & $\begin{array}{l}\text { Stevens et al. (1993), } \\
\text { Geerling et al. (2000) }\end{array}$ \\
\hline Tabersonine 16-hydroxylase & $\mathrm{T} 16 \mathrm{H}$ & Microsome & Schröder et al. (1999) \\
\hline$N$-methyltransferase & NMT & Thylakoid membrane & $\begin{array}{l}\text { Dethier and De Luca (1993), } \\
\text { De Luca and Cutler (1987) }\end{array}$ \\
\hline Desacetoxyvindoline 4-hydroxylase & $\mathrm{D} 4 \mathrm{H}$ & Cytosol & Vázquez-Flota et al. (1997) \\
\hline Deacetylvindoline 4-O-acetyltranferase & DAT & Cytosol & St-Pierre et al. (1998) \\
\hline 16-hydroxytabersonine $O$-methyltransferase & 16HT-OMT & $?$ & Cacace et al. (2003) \\
\hline Anhydrovinblastine synthase & AVLBS & Vacuole & Sottomayor et al. (1998) \\
\hline
\end{tabular}

brain (Verpoorte et al. 1998). Although the biosynthetic pathway for the production of terpenoid indole alkaloids (TIA) in C. roseus has been studied and more than 10 genes encoding specific enzymes have been discovered and partially characterized (Fig. 1, Table 3), the regulation of the pathway has been difficult to characterize.

The TIA biosynthesis pathway often involves multiple organellar compartments, resulting in transport limitation and sequestered pools of metabolites (Burlat et al. 2004; Kutchan 2005; St-Pierre et al. 1999; Verpoorte et al. 1997). The early steps of the terpenoid pathway (leading to geraniol) and the tryptophan pathway are expected to occur in plastids (Poulsen and Verpoorte 1991; Zhang et al. 2001). The conversion of tryptophan to tryptamine by tryptophan decarboxylase (TDC) occurs in the cytosol (De Luca and Cutler 1987; Stevens et al. 1993). Recent data have shown that two enzymes involved in secologanin biosynthesis are located in microsomes of $C$. roseus cells (Irmler et al. 2000). Deoxyloganin 7-hydroxylase (DL7H) catalyzes the conversion of 7-deoxyloganin to loganin and secologanin is then synthesized from loganin by secologanin synthase (SLS). Contin et al. (1999a, b) suggested that the conversion of loganin to secologanin may take place in or at the vacuoles. Since strictosidine synthase (STR) is localized in the vacuole, tryptamine must be transported across the tonoplast before coupling to secologanin can occur (McKnight et al. 1991).
Geraniol-10-hydroxylase (G10H), which catalyzes an early step in secologanin biosynthesis, is associated with provacuolar membranes (Collu et al. 2001; Madyastha et al. 1977). Strictosidine glucosidase (SGD), the enzyme catalyzing the deglucosylation of strictosidine, was suggested to be at least partly bound to the external face of the tonoplast (Stevens et al. 1993). However, in vivo localization studies showed that SGD is associated with the endoplasmic reticulum (ER; Geerlings et al. 2000). The $\mathrm{P}_{450}$-dependent monooxygenase tabersonine 16-hydroxylase $(\mathrm{T} 16 \mathrm{H})$, which is involved in the C-16 hydroxylation of tabersonine, was also shown to be associated with the microsome (Schröder et al. 1999). The enzyme possibly catalyzing the next step, 16-hydroxytabersonine $O$-methyltransferase (16HT-OMT), has been studied (Cacace et al. 2003). A $N$-methyltransferase (NMT) catalyzes the third-to-last step in vindoline biosynthesis and was found to be associated with thylakoid membranes (De Luca and Cutler 1987; Dethier and De Luca 1993). However, chloroplast development is apparently not necessary since NMT activity was also detected in etiolated seedlings. The last two steps in vindoline biosynthesis, catalyzed by desacetoxyvindoline 4-hydroxylase (D4H) and deacetylvindoline-4- $O$-acetyltransferase (DAT), occur in the cytosol (De Luca and Cutler 1987; StPierre et al. 1998; Vazquez-Flotä et al. 1997). Vindoline must then be channeled back to the vacuole where $3^{\prime}, 4^{\prime}$-anhydrovinblastine synthase 
(AVLBS), a basic peroxidase-like enzyme, necessary for coupling vindoline to catharanthine is localized (Sottomayor et al. 1998). None of the enzymes leading to catharanthine has been described. Overall, subcellular compartmentation of alkaloid metabolism is thus quite complex with biosynthetic enzymes localized in the cytosol, vacuole, provacuole, tonoplast membrane, endoplasmic reticulum, chloroplast stroma, thylakoid membranes and specific vesicles (Facchini 2001).

The compartmentation of these enzymes effectively sequesters toxic alkaloids and their biosynthetic intermediates away from the cytosol. The transport of alkaloid end-products or pathway intermediates into the storage site vacuoles may use specific transporters of different classes. Thus, alkaloid-specific transporters may be needed to deliver alkaloids to their proper accumulation sites. The subcellular trafficking of pathway intermediates also creates an important level of metabolic regulation that could not occur if enzymes and substrates diffused freely in the cytosol.

\section{Transport of terpenoid indole alkaloids across the tonoplast membrane in $C$. roseus}

Many TIA biosynthetic enzymes, including G10H, STR, DL7H, SLS, and AVLBS, are associated with the vacuole. Although the vacuolar transport of some TIA, such as ajmalicine, serpentine, catharanthine and vindoline, has been studied (Blom et al. 1991; Deus-Neumann and Zenk 1984; Guern et al. 1987; Meijer et al. 1993; Renaudin 1981, 1989; Renaudin and Guern 1982), the mechanisms involved in channeling pathway intermediates to specific subcellular compartments are still poorly understood. Since TIA biosynthesis was found to be related to the morphological changes of the vacuole (Neuman et al. 1983), the storage capacity of the vacuole may be a limiting factor in the production of a compound by the plant cell (Zenk 1978). Thus, it seems of interest to elucidate whether the vacuole plays a role in the metabolism of these compounds. Possible indole alkaloids and precursors transported into the vacuole isolated from $C$. roseus are discussed below.

\section{Tryptamine}

Tryptamine biosynthesis seems to occur in the cytosol (De Luca and Cutler 1987; Stevens et al. 1993). After overexpression of an enzyme converting tryptophan into tryptamine (TDC) in $C$. roseus cell cultures, no increase on alkaloid production was observed, suggesting that TDC is not the rate-limiting step in the alkaloid biosynthesis (Canel et al. 1998). Alkaloid accumulation was not enhanced when secologanin and tryptamine were added to the transgenic $C$. roseus cell cultures overexpressing the TDC and STR. Different compartmentation and subcellular relocation of intermediates could explain this effect (Stevens et al. 1993). The transport of this intermediate into the vacuoles is slightly inhibited by agents that collapse or prevent the formation of an $\mathrm{H}^{+}$ gradient and are inhibited by bafilomycin A1, a known vacuolar- $\mathrm{H}^{+}$ATPase inhibitor, suggests that the accumulation of this compounds is via V-ATPase transporters (Roytrakul 2004).

\section{Secologanin}

The iridoid glucoside secologanin is derived from the triose phosphate/pyruvate pathway (Contin et al. 1998). As the conversion of loganin to secologanin seems to occur in the vacuoles, where secologanin accumulates (Contin 1999a, b), it is tempting to speculate that SLS and maybe also DL7H are located at the vacuolar membrane. It would be interesting to know whether the conversion of 7-deoxyloganin to secologanin catalyzed by DL7H and SLS or the uptake of secologanin into vacuoles is the limiting factor in TIA production. In most cases, glucosylated compounds are transported into the vacuole by $\mathrm{H}^{+}$-antiporter mechanism (Martinoia et al. 2000), such as isovitexin and saponarin (Klein et al. 1996), oleanolic acid glucoside (Szakiel and Janiszowska 1992) and esculin (Werner and Matile 1985). A study of the uptake mechanism of this glucoside precursor into the vacuoles isolated from $C$. roseus showed an involvement of $\mathrm{ABC}$ transporter (Roytrakul 2004). This finding showed a new property of the vacuolar transport of the endogenous glucoside. 
Strictosidine

The central intermediate strictosidine (Nagakura et al. 1978; Stöckigt and Zenk 1977) may be an interesting model for studying vacuolar transport in $C$. roseus because this glucoside is synthesized in the vacuole where it is stored. The release of strictosidine was demonstrated in transgenic tobacco cell suspension upon feeding of secologanin (Hallard et al. 1997). Thus, it may be concluded that the storage of strictosidine inside the vacuole is specific to plant species. The vacuolar accumulation of strictosidine was effected by vanadate, $\mathrm{NH}_{4} \mathrm{Cl}$, CCCP and DCCD implied the regulation by an $\mathrm{ABC}$ transporter and a proton symport (Roytrakul 2004).

\section{Ajmalicine}

Ajmalicine is actively transported into isolated vacuoles against a concentration gradient with a $\mathrm{K}_{m}$ value of $1.67 \mu \mathrm{M}$ suggesting that this alkaloid is removed very efficiently from the cytosol (Blom et al. 1991; Deus-Neumann and Zenk 1984). The stimulatory effect of ATP on ajmalicine uptake is counteracted by $\mathrm{KNO}_{3}$ (Blom et al. 1991), the specific inhibitor of the V-ATPase transporter. Ajmalicine accumulates inside the vacuole by conversion into the charged serpentine, and an ion-trap is created to retain the alkaloid more efficiently in the vacuole (Blom et al. 1991). The rate of ajmalicine uptake was $81 \mathrm{pmol} / 10^{6}$ vacuole/90 min (Deus-Neumann and Zenk 1984). CCCP, gramicidine and $\mathrm{NH}_{4} \mathrm{Cl}$ as well as bafilomycin A1, had a negligible effect on the accumulation of ajmalicine in the presence of MgATP (Roytrakul 2004). The inhibition of MgATP-dependent accumulation exerted by vanadate (Roytrakul 2004). These results strongly imply that the ajmalicine transporter is belonging to the $\mathrm{ABC}$ transporter family.

\section{Tetrahydroalstonine}

Tetrahydroalstonine freely diffuses across the tonoplast in its neutral nonprotonated form and may be accumulated by an ion-trap in its charged protonated form like ajmalicine. The recent data (Roytrakul 2004) indicated that tetrahydroalsto- nine transport into the Catharanthus vacuole is weakly energized by MgATP, inhibited by vanadate suggesting that an $\mathrm{ABC}$ transporter may be involved, but with less efficiency than for ajmalicine.

Stemmadenine

Stemmadenine has been proposed as an intermediate leading to catharanthine and vindoline (Qureshi and Scott 1968a, b) indicating a possible branchpoint in the biosynthesis of alkaloids. However, the biosynthetic pathway from cathenamine to tabersonine through stemmadenine is still not characterized. Stemmadenine was efficiently taken up by isolated vacuoles irrespective of the presence of MgATP (Roytrakul 2004). Vanadate inhibited the accumulation of this alkaloid in the presence of MgATP into C. roseus vacuoles $(70 \%$ inhibition). Thus, stemmadenine may enter the vacuole by an vanadate-sensitive transporter which is not energized by ATP (Roytrakul 2004).

\section{Catharanthine}

Uptake of catharanthine in Catharanthus vacuoles was $31 \mathrm{pmol} / 10^{6}$ vacuole $/ 90 \mathrm{~min}$, with an apparent $\mathrm{K}_{\mathrm{m}}$ value of $2.5 \mu \mathrm{M}$ (Deus-Neumann and Zenk 1984). Catharanthine may be subjected to rapid turnover in $C$. roseus cells to unknown metabolites causing low levels of dimeric alkaloids in undifferentiated cell cultures. Recent finding showed that the carrier responsible for the accumulation of catharanthine is a member of ATP-energized ATP-binding cassette (ABC) transporters (Roytrakul 2004).

\section{Vindoline}

Transport of vindoline across the tonoplast has been characterized as an active, energy-requiring mechanism (Deus-Neumann and Zenk 1984; McCaskill et al. 1988), which is sensitive to the temperature and $\mathrm{pH}$ of the surrounding medium, stimulated by $\mathrm{K}^{+}$and $\mathrm{Mg}^{2+}$, and inhibited by DCCD and $\mathrm{Cu}^{2+}$ (Deus-Neumann and Zenk 1984). Deus-Neumann and Zenk (1984) determined a $\mathrm{K}_{m}$ value of $1.5 \mu \mathrm{M}$ for vindoline, while 
the rate of transport was $199 \mathrm{pmol} / 10^{6}$ vacuole/ 90 min. Our observations (Roytrakul 2004) indicated that vindoline is transported via an $\mathrm{ABC}$ transporter. However, vindoline may be accumulated by an ion-trap mechanism and coupled with catharanthine forming anhydrovinblastine inside the vacuoles.

\section{Transport of other metabolites through the tonoplast membrane in $C$. roseus cell culture}

Inorganic orthophosphate

Inorganic orthophosphate (Pi) might function as a regulatory factor of cytoplasmic $\mathrm{pH}$, a non-competitive inhibitor of the $\mathrm{H}^{+}$-pumps of both the plasma membrane and tonoplast (Mimura et al. 2000). Transport of $\mathrm{Pi}$ across the tonoplast membrane of $C$. roseus was strongly stimulated in the presence of Mg-ATP and Mg-pyrophosphate (Mg-PPi), and inhibited by bafilomycin A1 and concanamycin which are potent inhibitors of the vacuolar $\mathrm{H}^{+}$-ATPase (Massonneau et al. 2000). In the presence of $\mathrm{PPi}$, the tonoplast-bound inorganic pyrophosphatase from C. roseus cells is able to create a proton-gradient which can drive the synthesis of ATP from ADP and Pi. Proton gradient and ATP synthesis were suppressed by the protonic ionophore gramicidin D (Dupaix et al. 1989). This electrochemical gradient by the $\mathrm{H}^{+}$-pumps is found to be the driving force of $\mathrm{Pi}$ uptake, whereas the $\Delta \mathrm{pH}$ plays only a minor role (Massonneau et al. 2000).

\section{Glyphosate}

Glyphosate is distributed between the cytosolic and the vacuolar compartments, but the greater part is localized in the cytosol. The major elements increasing the cellular glyphosate uptake were $\mathrm{Ca}^{2+}, \mathrm{Mg}^{2+}$, and iron (Morin et al. 1997). Recently, Tilquin et al. (2000) demonstrated that glyphosate is taken up in $C$. roseus suspensions culture by an $\mathrm{Fe} /$ glyphosate co-transport, stimulated by the action of $\mathrm{Ca}^{2+}$. This co-transport system was found to occur with different degrees of efficiency in various plant cell suspensions, indicating that this glyphosate uptake process can be considered to be a general mechanism in plant cells.

\section{Malate}

This organic anion accumulates in the central vacuole of most plant cells. Malate has several important roles in plant vacuoles such as the maintenance of charge balance and $\mathrm{pH}$ regulation, as an osmolyte involved in the generation of cell turgor, and as a storage form of $\mathrm{CO}_{2}$. The transport rate was strongly stimulated when the $\mathrm{pH}$ of the incubation medium was decreased from pH 7.0 to 5.0 (Dietz 1992). Moreover, treatment with a pH 2 solution resulted in a gradual decrease of the malate content, indicating the operation of a biochemical $\mathrm{pH}$ regulation mechanism (Mimura 2000). Several lines of evidence (saturation kinetics, action of malate analogs and protein modifiers) support the concept that malate transport is mediated by a protein carrier which could be implicated in the uptake process of the protonated form. The malate transported in the vesicles was released by lowering the external malate concentration. The release was prevented by the anion transport inhibitor $\left(4,4^{\prime}\right.$ Diisothiocyanatostilbene-2,2'-disulfonic acid or DIDS) indicating the reversibility of the carrier (Bouyssou et al. 1990).

\section{Calcium ions}

The vacuole serves as a primary pool of free calcium ions in plant cells and the vacuole is a major source of $\mathrm{Ca}^{2+}$ for intracellular calcium signaling (Maeshima 2001). The $\mathrm{Ca}^{2+} / \mathrm{H}^{+}$antiporter together with the $\mathrm{Ca}^{2+}$-ATPase plays a key role in vacuolar $\mathrm{Ca}^{2+}$ accumulation. Zhao et al. (2001) have demonstrated that calcium influx plays a critical role in alkaloid biosynthesis in normal and elicited-C. roseus cell cultures. Further studies are needed to elucidate a functional relationship between $\mathrm{Ca}^{2+}$ transporters localized on the Catharanthus tonoplast and regulation of TIA biosynthesis. 


\section{Conclusions and perspectives}

Plant vacuoles are dynamic and can change morphologically and functionally to suit the needs of the cell. Rapid progress is being made in the areas of tonoplast transport and its regulation. The challenge is to merge views of vacuole function and biochemistry into a clear, unified picture that encompasses the dynamic nature of the vacuole.

An understanding of the biological processes that permit the synthesis and accumulation of terpenoid indole alkaloids in plants has advanced considerably over the past decade. This rapid progress has been facilitated by the availability of an impressive collection of alkaloid biosynthetic genes. These tools, combined with recent developments in plant genomics and proteomics, will promote efforts to identify more genes involved in the TIA pathways. TIA pathways are highly regulated and involve cell-, tissue-, development-, and environment-specific controls. Elaboration of the subcellular compartmentation of enzymes in TIA biosynthesis gives intriguing new views on the complexity of plant metabolism. Our emerging knowledge of the biochemistry, molecular biology, and cell biology of alkaloid biosynthesis will also lead to exciting opportunities to engineer TIA metabolism in transgenic plants.

Although this review has not answered how secondary metabolites are transported across the vacuolar membrane in $C$. roseus cells, principally due to a shortage of available information, it has highlighted which transporters, located in the tonoplast membrane, need to be considered.

\section{References}

Bartholomew DM, Van Dyk DE, Lau SMC, O'Keefe DP, Rea PA, Viitanen PV (2002) Alternate energydependent pathways for the vacuolar uptake of glucose and glutathione conjugates. Plant Physiol 130:1562-1572

Blom TJM, Sierra M, van Vliet TB, Franke-van Dijk MEI, de Koning P, van Iren F, Verpoorte R, Libbenga KR (1991) Uptake and accumulation of ajmalicine into isolated vacuoles of cultured cells of Catharanthus roseus (L.) G. Don and its conversion into serpentine. Planta 183:170-177

Blumwald E and Gelli A. 1997. Secondary inorganic ion transport at the tonoplast, In :The plant vacuole Leigh RA, Sanders D (eds) Advances in Botanical
Research, Vol 25, Academic Press, San Diego, London, Boston, New York, Sydney, Tokyo, Toronto, pp. 401-417

Böhm H, Franke J (1982) Accumulation and excretion of alkaloids by Macleaya microcarpa cell cultures. 1 . Experiments in solid medium. Biochem Physiol Pflanz 77:345-356

Boller T, Wiemken A (1986) Dynamics of vacuolar compartmentation. Annu Rev Plant Physiol 37:137-164

Bouyssou H, Canut H, Marigo G (1990) A reversible carrier mediates the transport of malate at the tonoplast of Catharanthus roseus cells. FEBS Lett 275:7376

Burlat V, Oudin A, Courtois M, Rideau M, St-Pierre B (2004) Co-expression of three MEP pathway genes and geraniol 10-hydroxylase in internal phloem parenchyma of Catharanthus roseus implicates multicellular translocation of intermediates during the biosynthesis of monoterpene indole alkaloids and isoprenoid-derived primary metabolites. Plant $\mathbf{J}$ 38:131-141

Cacace S, Schröder G, Wehinger E, Strack D, Schmidt J, Schröder J (2003) A flavonol $O$-methyltransferase from Catharanthus roseus performing two sequential methylations. Phytochemistry 62:127-137

Campbell EJ, Schenk PM, Kazan K, Penninckx IAMA, Anderson JP, Maclean DJ, Cammue BPA, Ebert PR, Manners JM (2003) Pathogen-responsive expression of a putative ATP-binding cassette transporter gene conferring resistance to the diterpenoid sclareol is regulated by multiple defense signaling pathways in Arabidopsis. Plant Physiol 133:1272-1284

Canel C, Lopes-Cardoso MI, Whitmer S, van der Fits L, Pasquali G, van der Heijden R, Hoge JHC, Verpoorte R (1998) Effects of overexpression of strictosidine synthase and tryptophan decarboxylase on alkaloid production by cell cultures of Catharanthus roseus. Planta 205:414-419

Castillo UF, Sakagami Y, Alonso-Amelot M, Ojika M (1999) Pteridanoside, the first protoilludane sesquiterpene glucoside as a toxic component of the neotropical bracken fern Pteridium aquilinum var. caudatum. Tetrahedron 55:12295-12300

Collu G, Unver N, Peltenburg-Looman AMG, van der Heijden R, Verpoorte R, Memelink J (2001) Geraniol 10-hydroxylase, a cytochrome P450 enzyme involved in terpenoid indole alkaloid biosynthesis. FEBS Lett 508:215-220

Constabel F, Koblitz H, Kirkpatrick JW, Rambold S (1980) Fusion of cell sap vacuoles subsequent to protoplast fusion. Can J Bot 58:1032-1034

Contin A, Van der Heijden R, Verpoorte R (1999a) Localization of secologanin in Catharanthus roseus cells. Acta Bot Gall 146:105-110

Contin A, Van der Heijden R, Verpoorte R (1999b) Accumulation of loganin and secologanin in vacuoles from suspension cultured Catharanthus roseus cells. Plant Sci 147:177-183

Contin A, van der Heijden R, Lefeber AWM, Verpoorte $\mathrm{R}$ (1998) The iridoid glucoside secologanin is derived from the novel triose phosphate/pyruvate pathway in 
a Catharanthus roseus cell culture. FEBS Lett 434:413-416

De Luca V, Cutler AJ (1987) Subcellular localization of enzymes involved in indole alkaloid biosynthesis in Catharanthus roseus. Plant Physiol 85:1099-1102

De Luca V, Marineau C, Brisson N (1989) Molecular cloning and analysis of a cDNA encoding a plant tryptophan decarboxylase: comparison with animal dopa decarboxylase. Proc Natl Acad Sci USA $86: 2582-2586$

Dean JV, Mills JD (2004) Uptake of salicylic acid 2-O- $\beta$ D-glucose into soybean tonoplast vesicles by an ATPbinding cassette transporter-type. Physiol Plant 120:603-612

Dethier M, De Luca V (1993) Partial purification of an $\mathrm{N}$-methyltransferase involved in vindoline biosynthesis in Catharanthus roseus. Phytochemistry 32:673-678

Deus-Neumann B, Zenk MH (1984) A highly selective alkaloid uptake system in vacuoles of higher plants. Planta 162:250-260

Deus-Neumann B, Zenk MH (1986) Accumulation of alkaloids in plant vacuoles does not involve an iontrap mechanism. Planta 167:44-53

Dietz KJ, Canut H, Marigo G (1992) Identification of an essential histidine residue at the active site of the tonoplast malate carrier in Catharanthus roseus cells. J Memb Biol 129:137-143

Dudler R, Sidler M (1998) Arabidopsis MDR genes: Molecular cloning and protein chemical aspects. Method Enzymol 292:162-173

Dupaix A, Johannin G, Arrio B (1989) ATP synthesis and pyrophosphate-driven proton transport in tonoplastenriched vesicles isolated from Catharanthus roseus. FEBS Lett 249:13-16

Endress R (1994) Plant cells as producers of secondary compounds. In: Plant cell biotechnology, SpringerVerlag, Berlin, pp. 121-242

Facchini PJ (2001) Alkaloid biosynthesis in plants: biochemistry, cell biology, molecular regulation, and metabolic engineering applications. Annu Rev Plant Physiol Plant Mol Biol 52:29-66

Frangne N, Eggmann T, Koblischke C, Weissenböck, Martinoia E, Klein M (2002) Flavone glucoside uptake into barley mesophyll and Arabidopsis cell culture vacuoles. Energization occurs by $\left(\mathrm{H}^{+}\right)$-antiport and ATP-binding cassette-type mechanisms. Plant Physiol 128:726-733

Gaedeke N, Klein M, Kolukisaoglu U, Forestier C, Muller A, Ansorge M, Becker D, Mamnun Y, Kuchler K, Schulz B, Mueller-Roeber B, Martinoia E (2001) The Arabidopsis thaliana ABC transporter AtMRP5 controls root development and stomata movement. EMBO J 20:1875-1887

Geerlings A, Martinez-Lozano Ibañez M, Memelink J, van der Heijden R, Verpoorte R (2000) Molecular cloning and analysis of strictosidine $\beta$-D-glucosidase, an enzyme in terpenoid indole alkaloid biosynthesis in Catharanthus roseus. J Biol Chem 275:3051-3056
Geibel M (1995) Sensitivity of the fungus Cytospora persoonii to the flavonoids of Prunus cerasus. Phytochemistry 38:599-601

Goodman CD, Casati P, Walbot V (2004) A multidrug resistance-associated protein involved in anthocyanin transport in Zea mays. Plant Cell 16:1812-1826

Guern J, Renaudin JP, Brown SC (1987) The compartmentation of secondary metabolites in plant cell cultures. In: Constabel F, Vasil IK (eds) Cell culture and somatic cell genetics of plants, vol. 4. Academic Press, San Diego, pp. 43-76

Hallard D, van der Heijden, Verpoorte R, Cardoso MIL, Pasquali G, Memelink J, Hoge JHC (1997) Suspension cultured transgenic cells of Nicotiana tabacum expressing tryptophan decarboxylase and strictosidine synthase cDNAs from Catharanthus roseus produce strictosidine upon secologanin feeding. Plant Cell Rep 17:50-54

Hopp W, Seitz HU (1987) The uptake of acylated anthocyanin into isolated vacuoles from a cell suspension culture of Daucus carota. Planta 170:74-85

Horio M, Gottesman MM, Pastan I (1988) Agents which reverse multidrug-resistance are inhibitors of $\left[{ }^{3} \mathrm{H}\right]$ vinblastine transport by isolated vesicles. Biochim Biophys Acta 1061:106-110

Irmler LS, Schröder LG, St-Pierre B, Crouch NP, Hotze1 M, Schmidt J, Strack D, Matern U, Schröder J (2000) Indole alkaloid biosynthesis in Catharanthus roseus: new enzyme activities and identification of cytochrome P450 CYP72A1 as secologanin synthase. Plant J 24:797-804

Jasinski M, Stukkens Y, Degand H, Purnelle B, MarchandBrynaert J, Boutry M (2001) A plant plasma membrane ATP binding cassette-type transporter is involved in antifungal terpenoid secretion. Plant Cell 13:1095-1107

Jauh GY, Phillips TE, Rogers JC (1999) Tonoplast intrinsic protein isoforms as markers for vacuolar functions. Plant Cell 11:1867-1882

Jones P, Vogt T (2001) Glycosyltransferases in secondary plant metabolism: tranquilizers and stimulant controllers. Planta 213:164-174

Klein M, Weissenbock G, Dufaud A, Gaillard C, Kreuz K, Martinoia E (1996) Different energization mechanisms drive the vacuolar uptake of a flavonoid glucoside and a herbicide glucoside. J Biol Chem 271:29666-29671

Klein M, Geisler M, Suh SJ, Kolukisaoglu HÜ, Azevedo L, Plaza S, Curtis MD, Richter A, Weder B, Schulz B, Martinoia E (2004) Disruption of AtMRP4, a guard cell plasma membrane ABCC-type ABC transporter, leads to deregulation of stomatal opening and increased drought susceptibility. Plant J 39:219-236

Klick S, Herrmann K (1988) Glucosides and glucose esters of hydroxybenzoic acids in plants. Phytochemistry 27:2177-2180

Kurdjian A (1982) Absorption and accumulation of nicotine by Acer pseudoplatanus and Nicotiana tabacum cells. Physiol Vég 20:73-83 
Kutchan TM (2005) A role for intra- and intercellular translocation in natural product biosynthesis. Curr Opin Plant Biol 8:292-300

Lee M, Lee K, Lee J, Noh EW, Lee Y (2005) AtPDR12 contributes to lead resistance in Arabidopsis. Plant Physiol 138:827-836

Leigh RA (1997) Solute compartmentation of vacuoles. Adv Bot Res 25:171-194

Li Z-S, Zhao Y, Rea PA (1995) Magnesium adenosine 5'triphosphate-energized transport of glutathione $S$ conjugates by plant vacuolar membrane vesicles. Plant Physiol 107:1257-1268

Liu G, Sanchez-Fernandez R, Li Z-S, Rea PA (2001) Enhanced multispecificity of Arabidopsis vacuolar multidrug resistance-associated protein-type ATPbinding cassette transporter, AtMRP2. J Biol Chem 276:8648-8656

Lu Y-P, Li ZS, Drozdowicz YM, Hortensteiner S, Martinoia E, Rea PA (1998) AtMRP2, an Arabidopsis ATP binding cassette transporter is able to transport glutathione $S$-conjugates and chlorophyll catabolites: functional comparisons with Atmrp1. Plant Cell 10:267-282

Lu Y-P, Li Z-S, Rea PA (1997) AtMRP1 gene of Arabidopsis encodes a glutathione $S$-conjugate pump: isolation and functional definition of a plant ATPbinding cassette transporter gene. Proc Natl Acad Sci USA 94:8243-8248

Luckner M, Diettrich B, Lerbs W (1980) Cellular compartmentation and chanelling of secondary metabolism in microorganisms and higher plants. Prog Phytochem 6:103-142

Madyastha KM, Ridgway JE, Dwyer JG, Coscia CJ (1977) Subcellular localization of a cytochrome P450 monooxygenase in vesicles of the higher plant Catharanthus roseus. J Cell Biol 72:302-313

Maeng H-J, Yoo H-J, Kim I-W, Song I-S, Chung S-J, Shim C-K (2002) P-glycoprotein-mediated transport of berberine across Caco- 2 cell monolayers. J Pharm Sci 91:2614-2621

Maeshima M (2000) Vacuolar $\mathrm{H}^{+}$-pyrophosphatase. Biochim Biophys Acta 1465:37-51

Maeshima M (2001) Tonoplast transporters: Organization and Function. Annu Rev Plant Physiol Plant Mol Biol 52:469-497

Martinoia E, Klein M, Gessler M, Sánchez-Fernández R, Rea PA (2001) Vacuolar transport of secondary metabolites and xenobiotics. In: Robinson D, Rogers J (eds) Vacuolar Compartments, CRC Series. Sheffield Academic Press, Sheffield, UK, pp. 221-253

Martinoia E, Massonneau A, Frangne N (2000) Transport processes of solutes across the vacuolar membrane of higher plants. Plant Cell Physiol 41:1175-1186

Martinoia E (1992) Transport processes in vacuoles of higher plants. Bot Acta 105:232-245

Massonneau A, Martinoia E, Dietz K J, Mimura T (2000) Phosphate uptake across the tonoplast of intact vacuoles isolated from suspension-cultured cells of Catharanthus roseus (L.) G. Don. Planta 211:390-395
Matern U, Reichenbach C, Heller W (1986) Efficient uptake of flavonoids into parsley (Petroselinum hortense) vacuoles requires acylated glycosides. Planta 167:183-189

Matile P, Jans B, Rickenbacher R (1970) Vacuoles of Chelidonium latex: lysosomal property and accumulation of alkaloids. Biochem Physiol Pflanzen 161:447-458

Matile P (1987) The sap of plant cells. New Phytol 105:126

McCaskill DG, Martin DL, Scott AI (1988) Characterization of alkaloid uptake by Catharanthus roseus (L.) G. Don protoplasts. Plant Physiol 87:402-408

McKnight TD, Bergey DR, Burnett RJ, Nessler CL (1991) Expression of enzymatically active and correctly targeted strictosidine synthase in transgenic tobacco plants. Planta 185:148-152

Meijer AH, Verpoorte R, Hoge JHC (1993) Regulation of enzymes and genes involved in terpenoid indole alkaloid biosynthesis in Catharanthus roseus. J Plant Res 3:145-164

Mende P, Wink M (1987) Uptake of the quinolizidine alkaloid lupanine by protoplasts and isolated vacuoles of suspension-cultured Lupinus polyphyllus cells. Diffusion or carrier-mediated transport? J Plant Physiol 129:229-242

Mimura T, Shindo C, Kato M, Yokota E, Sakano K, Ashihara H, Shimmen T (2000) Regulation of cytoplasmic $\mathrm{pH}$ under extreme acid conditions in suspension cultured cells of Catharanthus roseus: a possible role of inorganic phosphate. Plant Cell Physiol 41:424-431

Moons A (2003) Ospdr9, which encodes a PDR-type ABC transporter, is induced by heavy metals, hypoxic stress and redox perturbations in rice roots. FEBS Letts 553:370-376

Morin F, Vera V, Nurit F, Tissut M, Marigo G (1997) Glyphosate uptake in Catharanthus roseus cells: Role of a phosphate transporter. Pest Biochem Physiol 58:13-22

Nagakawa N, Konagai A, Fukui H, Tataba M (1984) Release and crystallization of berberine in the liquid medium of Thalictrum minus cell suspension cultures. Plant Cell Rep 3:254-257

Nagakura N, Hofle G, Coggiola D, Zenk MH (1978) The biosynthesis of the ipecac alkaloids and of ipecoside and alangiside. Planta Med 34:381-389

Neumann D, Krauss G, Heike M, George D (1983) Indole alkaloids formation and storage in cell suspension cultures of Catharanthus roseus. Planta Med 48:20-23

Otani M, Shitan N, Sakai K, Martinoia E, Sato F, Yazaki K (2005) Characterization of vacuolar transport of the endogenous alkaloid berberine in Coptis japonica. Plant Physiology 138:1939-1946

Paris N, Stanley CM, Jones RL, Rogers JC (1996) Plant cells contain two functionally distinct vacuolar compartments. Cell 85:563-572

Poulsen C, Verpoorte R (1991) Roles of chorismate mutase, isochorismate synthase and anthralinate synthase in plants. Phytochemistry 30:377-386 
Pradier JM, Barbier-Brygoo H, Ephritikhine G, Guern J (1988) Interaction of an alkaloid, serpentine, with the tonoplast of isolated vacuoles of Catharanthus roseus G. Don. Compt Rend Acd Sci serie III, Paris 297:283289

Qureshi AA, Scott AI (1968a) Biosynthesis of indole alkaloids: Sequential precursor formation and biological conversion in Vinca rosea. Chem Commun 16:948-950

Qureshi AA, Scott AI (1968b) Interconversion of Corynanthe, Aspidosperma, and Iboga alkaloids. A model for indole alkaloid biosynthesis. Chem Commun 16:945-946

Rataboul P, Alibert G, Boller T, Boudet AM (1985) Intracellular transport and vacuolar accumulation of $O$-coumaric acid glucoside in Melilotus alba mesophyll cell protoplasts. Biochim Biophys Acta 816:2536

Rea PA, Poole RJ (1993) Vacuolar $\mathrm{H}^{+}$-translocating pyrophosphatase. Annu Rev Plant Physiol Plant Mol Biol 44:157-182

Rea PA, Sanders D (1987) Tonoplast energization: two $\mathrm{H}^{+}$-pumps, one membrane. Physiol Plant 71:131-141

Rea PA, Li Z-S, Lu Y-P, Drozdowicz YM, Martinoia E (1998) From vacuolar GS-X pumps to multispecific ABC transporters. Annu Rev Plant Physiol Plant Mol Biol 49:727-760

Rea PA (1999) MRP subfamily ABC transporters from plants and yeast. J Exp Bot 50:895-913

Regnault-Roger C, Ribodeau M, Hamraoui A, Bareau I, Blanchard P, Gil-Munoz M-I, Barberan FT (2004) Polyphenolic compounds of mediterranean lamiaceae and investigation of orientational effects on Acanthoscelides obtectus (Say). J Stored Prod Res 40:395-408

Renaudin JP, Guern J (1982) Compartmentation mechanisms of indole alkaloids in cell suspension cultures of Catharanthus roseus. Physiol Vég 20:533-547

Renaudin JP (1981) Uptake and accumulation of an indole alkaloid, ${ }^{14} \mathrm{C}$-tabernanthine, by cell suspension cultures of Catharanthus roseus (L.) G. Don and Acer pseudoplatanus L. Plant Sci Lett 22:59-69

Renaudin JP (1989) Different mechanisms control the vacuolar compartmentation of ajmalicine in Catharanthus roseus cell cultures. Plant Physiol Biochem 27:613-621

Roytrakul S (2004) Transport of alkaloids and its precursor throuh the vacuolar membrane of Catharanthus roseus. Ph.D. Thesis. Leiden University, The Netherlands

Sanchez-Fernandez R, Ardiles-Diaz W, Van Montagu M, Inze D, May MJ (1998) Cloning and expression analyses of AtMRP4, a novel MRP-like gene from Arabidopsis thaliana. Mol Gen Genet 258:655-662

Sanchez-Fernandez R, Davies TGE, Coleman JOD, Rea PA (2001) The Arabidopsis thaliana ABC protein superfamily, a complete inventory. J Biol Chem 276:30231-30244
Santelia D, Vincenzetti V, Azzarello E, Bovet L, Fukao Y, Düchtig P, Mancuso S, Martinoia E, Geisler M (2005) MDR-like ABC transporter AtPGP4 is involved in auxin-mediated lateral root and root hair development. FEBS Letts 579:5399-5406

Sasabe M, Toyoda K, Shiraishi T, Inagaki Y, Ichinose Y (2002) cDNA cloning and characterization of tobacco ABC transporter: NtPDR1 is a novel elicitorresponsive gene. FEBS Lett 518:164-168

Sasaki T, Ezaki B, Matsumoto H (2002) A gene encoding multidrug resistance (MDR)-like protein is induced by aluminum and inhibitors of calcium flux in wheat. Plant Cell Physiol 43:177-185

Schröder G, Unterbusch E, Kaltenbach M, Schmidt J, Strack D, De Luca V, Schröder J (1999) Light-induced cytochrome P450-dependent enzyme in indole alkaloid biosynthesis: tabersonine 16-hydroxylase. FEBS Lett 458:97-102

Sefton MA, Francis L, Williams PJ (1994) Free and bound volatile secondary metabolites of Vitis vinifera grape cv. Sauvignon blanc. J Food Sci 59:142-147

Smart CC, Fleming AJ (1996) Hormonal and environmental regulation of a plant PDR5-like ABC transporter. J Biol Chem 271:19351-19357

Sottomayor M, Lopez-Serrano M, DiCosmo F, Ros-Barcelo A (1998) Purification and characterization of $\alpha$ $3^{\prime}, 4^{\prime}$-anhydrovinblastine synthase (peroxidase-like) from Catharanthus roseus (L.) G. Don. FEBS Lett 428:299-303

Stevens LH, Blom TJM, Verpoorte R (1993) Subcellular localization of tryptophan decarboxylase, strictosidine synthase and strictosidine $\beta$-D-glucosidase in suspension cultured cells of Catharanthus roseus and Tabernaemontana divaricata. Plant Cell Rep 12:573-576

Stöckigt J, Zenk MH (1977) Strictosidine (Isovincoside): the key intermediate in the biosynthesis of monoterpenoid indole alkaloids. J Chem Soc Chem Commun 18:646-648

St-Pierre B, Laflamme P, Alarco A, De Luca V (1998) The terminal $O$-acetyltransferase involved in vindoline biosynthesis defines a new class of proteins responsible for coenzyme A-dependent acyl transfer. Plant J 14:703-713

St-Pierre B, Vazquez-Flota FA, De Luca V (1999) Multicellular compartmentation of Catharanthus roseus alkaloid biosynthesis products predicts intercellular translocation of a pathway intermediate. Plant Cell 11:887-900

Szakiel A, Janiszowska W (2002) The mechanism of oleanolic acid monoglycosides transport into vacuoles isolated from Calendula officinalis leaf protoplasts. Plant Physiol Biochem 40:203-209

Sze H, Li X, Palmgren MG (1999) Energization of the plant cell membranes by $\mathrm{H}^{+}$-pumping ATPases: biosynthesis and regulation. Plant Cell 11:677-689

Taiz L (1992) The plant vacuole. J Exp Biol 172:113-122

Terasaka K, Sakai K, Sato F, Yamamoto H, Yazaki K (2003) Thalictrum minus cell cultures and ABC-like transporter. Phytochemistry 62:483-489 
Terrier N, Deguilloux C, Sauvage F-X, Martinoia E, Romieu C (1998) Proton pumps and anion transport in Vitis vinifera: The inorganic pyrophosphatase plays a predominant role in the energization of the tonoplast. Plant Physiol Biochem 36:367-377

Theodoulou FL, Clark IM, He X-L, Pallett KE, Cole DJ, Hallahan DL (2003) Xenobiotics induce glutathione transferases and multidrug resistance associated protein in wheat. Pest Manag Sci 59:202-214

Thomas C, Rajagopal A, Windsor B, Dudler R, Lloyd A, Roux SJ (2000) A role for ectophosphatase in xenobiotic resistance. Plant Cell 12:519-534

Tilquin M, Peltier JP, Marigo G (2000) Mechanisms for the coupling of iron and glyphosate uptake in Catharanthus roseus cells. Pest Biochem Physiol 67:145-154

Tommasini R, Vogt E, Fromentau M, Hörtensteiner S, Matile P, Amrhein N, Martinoia E (1998) An ABCtransporter of Arabidopsis thaliana has both glutathione- $S$-conjugate and chlorophyll catabolite transport activity. Plant J 13:773-780

van den Brûle S, Müller A, Fleming AJ, Smart CC (2002) The ABC transporter SpTUR2 confers resistance to the antifungal diterpene sclareol. Plant J 30:649-662

van den Brûle S, Smart CC (2002) The plant PDR family of ABC transporters. Planta 216:95-106

Vázquez-Flota F, De Carolis E, Alarco A, De Luca V (1997) Molecular cloning and characterization of deacetoxyvindoline 4-hydroxylase, a 2-oxoglutaratedependent dioxygenase involved in the biosynthesis of vindoline in Catharanthus roseus (L.) G. Don. Plant Mol Biol 34:935-948

Verpoorte R, van der Heijden R, Memelink J (1998) Plant biotechnology and the production of alkaloids Prospects of metabolic engineering. In: Cordell GA (ed) The Alkaloids, Vol 50. Academic Press, San Diego, pp 453-508

Verpoorte R, van der Heijden R, Moreno PRH (1997) Biosynthesis of terpenoid indole alkaloids in Catharanthus roseus cells. In: Cordell GA (ed) The Alkaloids, vol. 49. Academic Press, New York, pp 221-299

Walle UK, Walle T (1998) Taxol transport by human intestinal epithelial Caco-2 cells. Drug Metab Dispos 26:343-6

Wang W, Takezawa D, Poovaiah BW (1996) A potato cDNA encoding a homologue of mammalian multidrug resistant P-glycoprotein. Plant Mol Biol 31:683687
Warzecha H, Obitz P, Stöckigt J (1999) Purification, partial amino acid sequence and structure of the product of raucaffricine- $O$ - $\beta$-D-glucosidase from plant cell cultures of Rauwolfia serpentina. Phytochemistry 50:1099-1109

Werner C, Matile P (1985) Accumulation of coumarylglucosides in vacuoles of barley mesophyll protoplasts. J Plant Physiol 118:237-249

Windsor B, Rpux SJ, Lloyd A (2003) Multiherbicide tolerance conferred by AtPgp1 and apyrase overexpression in Arabidopsis thaliana. Nature Biotechnol 21:428-433

Wink M (1997a) Compartmentation of secondary metabolites and xenobiotics in plant vacuoles. Adv Bot Res 25:141-169

Wink M (1997b) Compartmentation of secondary metabolites and xenobiotics in plant vacuoles. In: Leigh RA, Sanders D, Callow JA (eds) The Plant Vacuole: Advances in Botanical Research, Vol. 25. Academic Press, London, pp. 141-170

Yasaki K, Shitan N, Takamatsu H, Ueda K, Sato F (2001) A novel Coptis japonica multidrug-resistant protein preferentially expressed in the alkaloid-accumulating rhizome. J Exp Bot 52:877-879

Yazaki K, Inushima K, Kataoka M, Tabata M (1995) Intracellular localization of UDPG: $p$-hydroxybenzoate glucosyltransferase and its reaction product in Lithospermum cell cultures. Phytochemistry 38:11271130

Zenk MH. 1978. The impact of plant cell culture on industry. In: Frontiers of plant tissue culture 1978, pp. 1-13, Thorpe, T.A. ed Int Assoc. Plant Tissue Culture, Calgary, Canada

Zhang XH, Brotherton JE, Widholm JM, Portis AR Jr (2001) Targeting a nuclear anthranilate synthase $\alpha$ subunit gene to the tobacco plastid genome results in enhanced tryptophan biosynthesis. Return of a gene to its pre-endosymbiotic origin. Plant Physiol 127:131141

Zhao J, Hu Q, Guo Y-Q, Zhu W-H (2001) Elicitor-induced indole alkaloid biosynthesis in Catharanthus roseus cell cultures is related to $\mathrm{Ca}^{2+}$ influx and the oxidative burst. Plant Sci 161:423-431

Zhen R-G, Kim EJ, Rea PA (1997) The molecular and biochemical basis of pyrophosphate-energized proton translocation at the vacuolar membrane. Adv Bot Res 25:297-337 